\title{
Chest pain and exacerbations of bronchiectasis
}

This article was published in the following Dove Press journal:

International Journal of General Medicine

6 December 2012

Number of times this article has been viewed

Paul T King ${ }^{1,2}$

Stephen R Holdsworth ${ }^{2}$

Michael Farmer'

Nicholas J Freezer'

Peter W Holmes'

'Department of Respiratory and

Sleep Medicine, ${ }^{2}$ Monash University

Department of Medicine, Monash

Medical Centre, Melbourne, Victoria,

Australia
Correspondence: Paul King

Monash University Department

of Medicine, Monash Medical Centre,

Melbourne, Victoria, Australia, 3168

Tel +6I 395946666

Fax +6I 395946495

Email paul.king@monash.edu
Background: Bronchiectasis is a common disease and a major cause of respiratory morbidity. Chest pain has been described as occurring in the context of bronchiectasis but has not been well characterized. This study was performed to describe the characteristics of chest pain in adult bronchiectasis and to define the relationship of this pain to exacerbations.

Subjects and methods: We performed a prospective study of 178 patients who were followed-up for 8 years. Subjects were reviewed on a yearly basis and assessed for the presence of chest pain. Subjects who had chest pain at the time of clinical review by the investigators were included in this study. Forty-four patients $(25 \%)$ described respiratory chest pain at the time of assessment; in the majority of cases 39/44 (89\%), this occurred with an exacerbation and two distinct types of chest pain could be described: pleuritic $(n=4)$ and non-pleuritic $(n=37)$, with two subjects describing both forms. The non-pleuritic chest pain occurred most commonly over both lower lobes and was mild to moderate in severity. The pain subsided as patients recovered.

Conclusion: Non-pleuritic chest pain occurs in subjects with bronchiectasis generally in association with exacerbations.

Keywords: sputum, collapse, bronchitis, airway obstruction

\section{Background}

Chest pain may arise from a number of issues, including cardiac, respiratory, gastrointestinal, and chest wall conditions. Respiratory chest pain is traditionally thought to result from stimulation of nerves in the parietal pleura, which manifests as pleuritic chest pain. However, the lungs also have visceral sensory innervation. The visceral pain pathway in the lung may be activated by mechanical, irritant, or chemical stimuli and convey impulses via the vagus nerve to the brainstem. These visceral sensory receptors are concentrated in the upper airway and at the bronchial bifurcations. Stimulation of these receptors most commonly produces a burning retrosternal sensation. ${ }^{1-3}$

Bronchiectasis is a condition that is defined by the presence of permanent and abnormal airway dilatation and has had a relatively low profile until recently. However, the widespread use of high-resolution computed tomography (HRCT) scanning has lately made the diagnosis of this condition much easier and led to the realization that this condition is very common and a major cause of respiratory morbidity. ${ }^{4,5}$ Bronchiectasis is characterized by chronic airway infection and marked inflammation. ${ }^{4,6}$ It is expected that the chronic airway inflammation and associated sputum production activates the airway sensory receptors. 
There are limited data describing the clinical features of bronchiectasis. We have been studying a cohort of subjects with this condition for a number of years. It is well recognized that chest pain occurs in patients with bronchiectasis, but there is no literature that we are aware of that describes the characteristics of this symptom. Our subjects described a particular form of non-pleuritic chest pain that appeared to occur mainly with exacerbations. This study was undertaken to define the nature of the chest pain in more detail by prospectively assessing patients at the actual time of their chest pain.

\section{Subjects and methods}

A cohort of 178 consecutive subjects with bronchiectasis was followed-up prospectively at the Monash Medical Centre (MMC) between 2000 and 2009. Bronchiectasis had been diagnosed by HRCT scanning using standard criteria ${ }^{7}$ and computed tomography scans were scored using a previously published method. ${ }^{8}$ Ethical approval for this project was obtained from the ethics committee at the MMC and informed consent was obtained from all subjects.

Subjects were interviewed either at home or at the MMC on a yearly basis. All subjects were outpatients who lived in the community with a low incidence of comorbid disease. Only five subjects were current smokers, although 33 had a smoking history. Thirteen subjects were classified as having coexistent chronic obstructive pulmonary disease (COPD). Subjects were interviewed and asked about their current symptoms, volume of sputum, comorbid disease, and medications.

Screening for underlying causation included clinical interview; cystic fibrosis mutation analysis; aspergillus precipitin test; immunoglobulin assessment; full blood examination; ciliary, neutrophil, and lymphocyte function tests; and alpha-1 antitrypsin level assessment. No subject had cystic fibrosis and most subjects were classified as having idiopathic disease (116/178). The other subjects had a variety of different causative factors, with 16 post-infectious, eight with immunoglobulin G subclass deficiency, four with allergic bronchopulmonary aspergillosis, four with hypogammaglobulinemia, one with Kartagener's syndrome, one with chronic lymphocytic leukemia, and one with Young's syndrome. Subjects were not currently on major immunosuppressive therapy. Forty-three subjects were taking inhaled corticosteroids. Sputum samples were obtained from subjects for microbiologic analysis.

Subjects were asked specifically about the presence of chest pain at the time of review. Subjects were well known to the interviewer $(\mathrm{PK})$ and were able to give a clear history of chest pain. Patients were asked about the site, duration, aggravating and relieving factors, and associated symptoms of their chest pain. They were also asked about classic features of pleuritic chest pain - sharp pain that is worse on inspiration and non-respiratory chest pain (type of pain, relation to inspiration/movement and radiation). The eleven-point Numerical Rating Scale was used to quantify pain, with 0 meaning no pain and 10 meaning the worst pain imaginable. There is no widely accepted instrument used to assess respiratory chest pain, but the Numerical Rating Scale

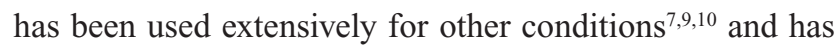
been used to assess pain in lung cancer. ${ }^{11}$

Patients were assessed for the existence of possible contributing causes to chest pain. Subjects were asked if they had any relevant history of documented ischemic heart disease, biliary tract disease, reflux, and/or musculoskeletal/ fibromyalgia and were then asked specifically about angina, palpitations, orthopnea, swelling of ankles; any relation of the pain to food and swallowing; any radiation of pain; and tenderness to palpation over the chest wall. Respiratory, cardiovascular, and gastrointestinal examinations were performed. Assessment of the chest wall was also performed to assess for the presence of musculoskeletal pain. When appropriate, X-ray and cardiac investigations were done.

The association of chest pain with exacerbations of bronchiectasis was also assessed. Exacerbations were defined as either the presence of at least one of: increased sputum volume, increased dyspnea, and increased sputum purulence or as a sustained acute worsening requiring a change in medication. Exacerbations were treated with narrow-spectrum antibiotics and chest physiotherapy. Subjects were reviewed in 2-8 weeks and asked about the resolution of pain.

Results are expressed as number and percentage, mean \pm standard deviation (SD) for normally distributed data, and median and range for nonparametric data. $T$-testing, Mann-Whitney $U$ testing or chi-square testing was used to compare differences between groups. Data were analyzed using Prism 5 software (GraphPad, San Diego, CA, USA).

\section{Results}

The average age of members of the study cohort was 58 years and members were predominantly female. There was a moderate incidence of coexistent disease. Lung function testing demonstrated moderate airflow obstruction in the cohort, which is a typical finding in bronchiectasis. ${ }^{4-6,8}$ The dominant pathogens grown in the sputum were Haemophilus influenzae and Pseudomonas aeruginosa. Baseline characteristics are listed in Table 1. 
Table I Baseline characteristics of bronchiectasis cohort of 178 patients (at time of initial review)

\begin{tabular}{ll}
\hline Age & $58 \pm$ I5 years (mean \pm SD) \\
Sex & \\
Male & 62 patients (35\%) \\
Female & 116 patients (65\%) \\
Smoking history & 44 patients (25\%) \\
$\quad$ Pack years & $24 \pm 15$ (mean \pm SD) \\
Comorbidities & \\
$\quad$ Asthma & 22 patients (I2\%) \\
Hypertension & 16 patients (9\%) \\
Cardiovascular disease & 14 patients (8\%) \\
COPD & 13 patients (8\%) \\
Pathogens in sputum & \\
Haemophilus influenzae & 62 patients (35\%) \\
Pseudomonas aeruginosa & 23 patients (13\%) \\
No growth & 48 patients (28\%) \\
\hline
\end{tabular}

Abbreviations: COPD, chronic obstructive pulmonary disease; SD, standard deviation.

Forty-four subjects described the presence of respiratory chest pain at the time of clinical assessment (by PK). In the majority of cases, 39/44 (89\%), this occurred with an exacerbation and two distinct types of respiratory chest pain could be identified: pleuritic $(n=4)$ and non-pleuritic $(\mathrm{n}=37)$, with two subjects describing both types.

There was no clear difference between subjects who had chest pain and those who did not. There were no statistical differences in symptoms, spirometry, and extent of disease on HRCT between the two groups (Table 2).

The non-pleuritic chest pain in the 37 subjects (with an exacerbation) was described as being a continuous squeezing

Table 2 Features of subjects with and without non-pleuritic chest pain in exacerbations (at the time of initial review)

\begin{tabular}{lll}
\hline & $\begin{array}{l}\text { Patients without } \\
\text { pain }(\mathbf{n}=\mathbf{1 4 1})\end{array}$ & $\begin{array}{l}\text { Patients with } \\
\text { chest pain }(\mathbf{n}=\mathbf{3 7})\end{array}$ \\
\hline $\begin{array}{l}\text { Age (years) } \\
\text { Sex ratio of group }\end{array}$ & $\begin{array}{l}59 \pm 15 \\
\text { Symptoms }\end{array}$ & $\begin{array}{l}58 \pm 17 \\
13 \text { male/92 female }\end{array}$ \\
$\quad \begin{array}{l}\text { Productive cough } \\
\text { Daily sputum }\end{array}$ & $94 \%$ & $93 \%$ \\
MRC dyspnea scale & $67 \%$ & $74 \%$ \\
Daily sputum (mL) & $2.6 \pm 1.1$ & $2.4 \pm 1.2$ \\
Exacerbation (per year) & $30(0-10)$ & $34(0-200)$ \\
Spirometry & & $3(0-10)$ \\
FEV (\% predicted) & $66 \pm 23$ & \\
FVC (\% predicted) & $79 \pm 20$ & $61 \pm 29$ \\
HRCT score & $31 \pm 15$ & $81 \pm 22$ \\
\hline
\end{tabular}

Notes: Results are expressed as mean \pm standard deviation or median and range. aScored as described in McGuinness and Naidich. ${ }^{7}$

Abbreviations: MRC, Medical Research Council; FEV, forced expiratory volume in I second; FVC, forced vital capacity; HRCT, high-resolution computed tomography. type of chest pain that was moderate in severity (rated on a pain scale of ranging from 0 to 10 as $3.8 \pm 1.4$ [mean and SD]). The pain did not occur in bouts and was not triggered by coughing. The pain was not myalgic in character. The distribution of the pain was described as predominantly occurring in the lower lobes, either unilaterally (22/37 subjects) or bilaterally (12/37 subjects). Thirty-three subjects (89\%) described chest pain occurring over an area corresponding to a lobe with known bronchiectasis (on HRCT). Thirteen subjects also described a component of substernal discomfort, possibly suggesting tracheal irritation. The characteristics of the chest pain are summarized in Table 3.

The non-pleuritic chest pain often came on early in the exacerbation, with 19 subjects (51\%) reporting the pain as being present before change in cough, sputum characteristics, or dyspnea. The chest pain tended to persist throughout the exacerbations with some mild fluctuations and it subsided as the patient recovered. There were no clear associated aggravating or relieving factors. Five subjects described non-pleuritic chest pain occurring without an exacerbation; this lasted from 1 to 8 days and settled spontaneously.

The dominant physical finding in subjects with this chest pain was the presence of localized crackles, present in 29 out of 37 subjects. Other common findings were localized wheeze (ten subjects), decreased air entry (nine subjects), and tachycardia (eight subjects). No subject had chest wall tenderness.

Twenty-nine subjects had chest X-rays performed when they had pain and four subjects had HRCT scans done with pain. Fifteen out of the 29 chest X-rays demonstrated focal changes that corresponded to the area of pain with the presence of either atelectasis/collapse (12/15) and/or consolidation (6/15). HRCT demonstrated the presence of collapse/atelectasis/consolidation in three subjects. Typical X-rays are shown in Figures 1 and 2. Subsequent follow-up X-rays (done 2-12 weeks later) in 14 subjects demonstrated resolution of atelectasis/collapse or consolidation.

Table 3 Characteristics of non-pleuritic chest pain occurring in exacerbations of bronchiectasis in 37 patients

\begin{tabular}{ll}
\hline Severity (pain scale 0-10) & $3.8 \pm 1.4$ (mean \pm SD) \\
Distribution & \\
$\quad$ Unilateral lower zone & 22 patients $(59 \%)$ \\
Bilateral lower zone & 12 patients $(32 \%)$ \\
$\quad$ Other & 3 patients $(8 \%)$ \\
First symptom in exacerbation & 19 patients (5I\%) \\
Duration (time between onset and & $8.8 \pm 3.7$ days (mean \pm SD) \\
resolution) &
\end{tabular}

Abbreviation: SD, standard deviation. 

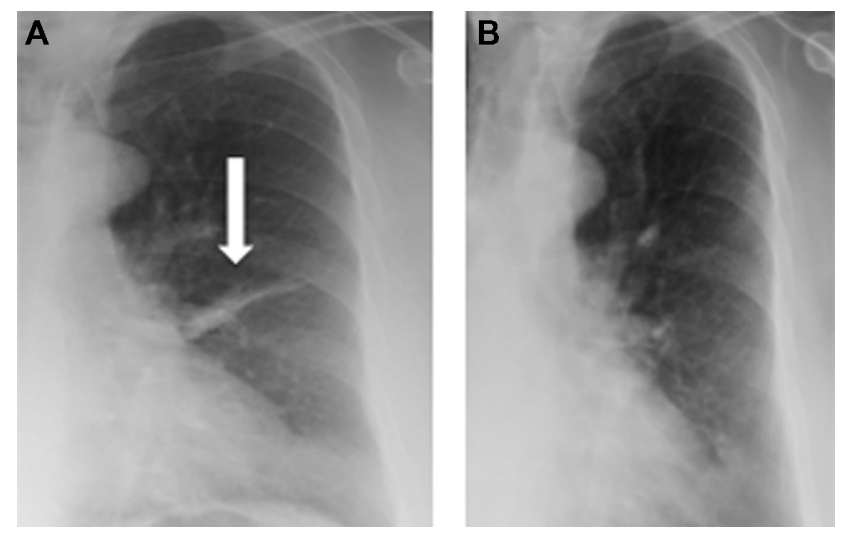

Figure I (A) Chest X-ray showing atelectasis in the lingular segment of the left lung. The subject complained of typical non-pleuritic aching chest pain over the left upper chest, as described in this article. (B) Follow-up X-ray showing resolution of atelectasis.

\section{Discussion}

In this paper, we have described a distinctive type of non-pleuritic chest pain in bronchiectasis that occurred predominantly in association with acute exacerbations

The lung parenchyma is often considered to be pain insensitive. ${ }^{12}$ The passage of a needle into the lung (for biopsy) does not cause pain ${ }^{13,14}$ and lung cancer is generally classified as being painless unless there is involvement of the parietal pleura. However, the lung airways (trachea/bronchi) have a dense sensory network. ${ }^{1,2,12,15}$ Inflammation of the trachea or the bronchi induces a sensation of burning/ache. In contrast to the well-defined pain of pleuritic involvement, this pain arising from the airways is poorly localized and most commonly described as retrosternal by patients.

There are three main types of sensory receptors in the airways. The slowly adapting stretch receptors are
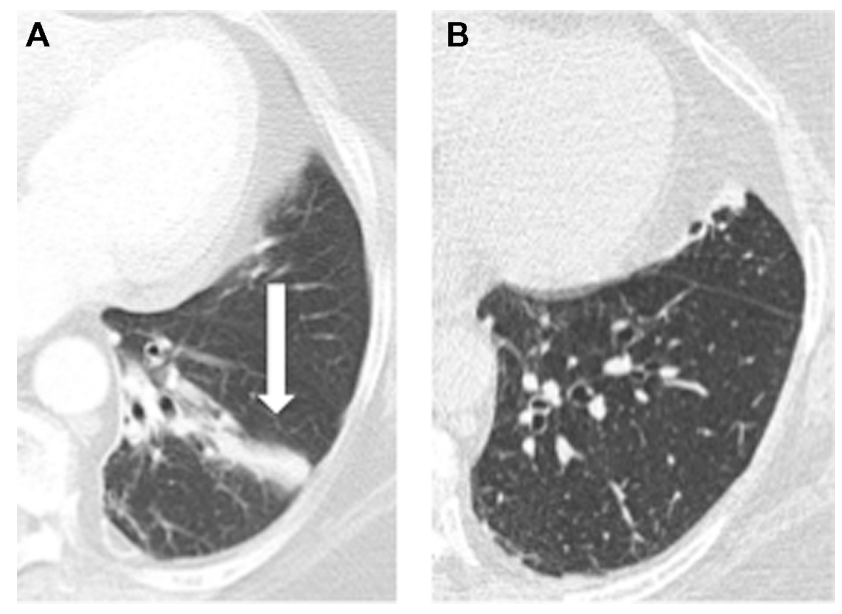

Figure 2 (A) High-resolution computed tomography (CT) scan showing left basal atelectasis/bronchiectasis. The patient complained of acute onset of bilateral nonpleuritic lower chest pain. (B) Follow-up CT showing with resolution of symptoms. mechanoreceptors located in the smooth muscle of the large airways that respond to lung inflation. ${ }^{1,2,16}$ The rapidly adapting receptors have a widespread distribution in the smaller airways (distal bronchi and bronchioles) and respond predominantly to rapid lung deflation, bronchial deformation, and mucosal irritation. ${ }^{1,3,17}$ The final form of sensory receptors are the $\mathrm{C}$-fibers, which are predominantly chemosensitive (to a variety of factors, including $\mathrm{pH}$ and arachidonic acid metabolites) but also respond to mechanical stimuli. ${ }^{1,18-20}$

Severe airway inflammation with production of large quantities of purulent sputum is a standard feature of bronchiectasis. ${ }^{21}$ Sputum retention with associated atelectasis and collapse is a prominent feature. Subjects with bronchiectasis have periodic acute deteriorations in their clinical state with increased sputum production that are classified as exacerbations. ${ }^{22}$

The definition of an exacerbation of bronchiectasis is not standardized. ${ }^{22}$ Different studies have used the Anthonisen criteria, ${ }^{8}$ a combination of clinical and X-ray changes, ${ }^{23}$ and the Anthonisen criteria in association with the prescription of antibiotics. ${ }^{24}$ Rodriguez-Roisin ${ }^{25}$ proposed a definition of COPD exacerbations that has now been incorporated into the GOLD (Global initiative for chronic Obstructive Lung Disease) guidelines for the management of COPD. We applied this definition to our bronchiectasis cohort, as it appears to be widely accepted and similar to COPD, subjects with bronchiectasis develop progressive airway obstruction, ${ }^{8,26}$ and cough is a dominant symptom. ${ }^{21}$

Exacerbations of chronic bronchitis are thought to be only associated with pleuritic chest pain. ${ }^{27}$ This is surprising, as the inflammation and mechanical factors would be expected to stimulate airway sensory receptors and activate visceral pain pathways. Nicotra et al listed chest pain in a cohort of subjects with bronchiectasis as being predominantly pleuritic in origin, which is in contrast to the current study. ${ }^{28}$ Nicotra et al's study was a case note review and it is not clear how chest pain was assessed in this cohort. To our knowledge, the present study is the first to clearly describe non-pleuritic chest pain in exacerbations of bronchiectasis.

The mechanism of the chest pain in our cohort of patients was unclear. There were no clear features differentiating those who had pain and those who did not. We considered two major explanations for the pain that our subjects experienced: (1) production of inflammatory mediators and (2) activation of stretch/mechanoreceptors.

The pathogenesis of bronchiectasis is characterized by intense bronchial inflammation that is mediated by neutrophils, macrophages, and lymphocytes. A large 
variety of inflammatory mediators are involved, ${ }^{29}$ including arachidonic acid metabolites. ${ }^{30}$ Exacerbations are associated with increased production of mediators. ${ }^{22,29}$ However, there appeared to be no clear difference between the patients who had chest pain and those who did not. Both groups had similar symptoms, lung function, extent of disease on HRCT, and frequency of exacerbations.

In this group of subjects, the chest pain may have arisen from localized lung collapse associated with airway secretions/sputum. Atelectasis or lobar collapse is a classic manifestation of acute bronchial obstruction and generally affects the lower lobes of the lungs. In support of this possibility, the resolution of symptoms presumably occurs after airway inflammation improves and pulmonary re-expansion occurs and, in our cohort, half of the subjects had evidence of X-ray changes that would support this hypothesis. We have also previously described a subject with bronchiectasis who had four documented episodes of chest pain that were the same as those of patients in the current cohort: with each episode of chest pain there was left lower lobe collapse present on chest X-ray or computed tomography and when the lobar collapse resolved, the pain resolved. ${ }^{31}$

Acute obstruction to other viscera such as the intestine or biliary tract causes significant pain. The principal activation is thought to be through the stretch receptors, with pain conducted by $\mathrm{C}$-fibers. ${ }^{32}$ Chronic bronchial obstruction, as may occur with a bronchogenic tumor, does not generally cause pain. Acute airway obstruction could potentially activate the rapidly adapting receptor and C-fiber sensory receptors.

This study is limited by the difficulty of assessing acute symptoms in these patients. The assessment was primarily based on clinical criteria. However, we did follow-up this cohort for a number of years and significant expertise was utilized in the clinical assessment of these subjects. Further, the data presented in this study were obtained at the time of pain. The primary aim was not to assess all the features of an exacerbation of bronchiectasis but to describe the features of chest pain in this context. We are not aware of any other study on bronchiectasis that has assessed this common symptom in this way or in this amount of detail.

\section{Conclusion}

Non-pleuritic chest pain is common in bronchiectasis and, in this cohort, occurred predominantly with exacerbations. Recognition of this symptom may facilitate detection of exacerbations.

\section{Acknowledgment}

This work was funded by a grant from the National Health and Medical Research Council of Australia (to PK).

\section{Disclosure}

The authors declare no conflicts of interest in this work.

\section{References}

1. Fillenz M, Widdicombe JG. Receptors of the lungs and airways. In: Neil E, editor. Handbook of Sensory Physiology: Enteroceptors. Berlin: Springer-Verlag; 1971:81-112.

2. Paintal AS. The visceral sensations, some basic mechanisms. In: Cervero F, Morrison J, editors. Progress in Brain Research. Visceral Sensation. Amsterdam: Elsevier; 1986;67:3-19.

3. Widdicombe JG. Sensory innervation of the lungs and airways. Prog Brain Res. 1986;67:49-64.

4. King PT, Holdsworth SR, Freezer NJ, Holmes PW. Bronchiectasis Intern Med J. 2006;36(11):729-737.

5. Patel IS, Vlahos I, Wilkinson TM, et al. Bronchiectasis, exacerbation indices, and inflammation in chronic obstructive pulmonary disease. Am J Respir Crit Care Med. 2004;170(4):400-407.

6. Barker AF. Bronchiectasis. N Engl J Med. 2002;346(18):1383-1393.

7. McGuinness G, Naidich DP. CT of airways disease and bronchiectasis. Radiol Clin North Am. 2002;40(1):1-19.

8. King PT, Holdsworth SR, Freezer NJ, Villanueva E, Gallagher M, Holmes PW. Outcome in adult bronchiectasis. COPD. 2005;2(1):27-34

9. Lynch ME, Clark AJ, Sawynok J, Sullivan MJ. Topical 2\% amitriptyline and $1 \%$ ketamine in neuropathic pain syndromes: a randomized, doubleblind, placebo-controlled trial. Anesthesiology. 2005;103(1):140-146.

10. Maier C, Hildebrandt J, Klinger R, Henrich-Eberl C, Lindena G; MONTAS Study Group. Morphine responsiveness, efficacy and tolerability in patients with chronic non-tumor associated pain results of a double-blind placebo-controlled trial (MONTAS). Pain. 2002;97(3): 223-233.

11. Hollen PJ, Gralla RJ, Kris MG, McCoy S, Donaldson GW, Moinpour CM. A comparison of visual analogue and numerical rating scale formats for the Lung Cancer Symptom Scale (LCSS): does format affect patient ratings of symptoms and quality of life? Qual Life Res. 2005;14(3): 837-847.

12. Cervero F. Sensory innervation of the viscera: peripheral basis of visceral pain. Physiol Rev. 1994;74(1):95-138.

13. Lewis T. Pain. New York, NY: MacMillan; 1942.

14. Bonica JJ. The Management of Pain, 2nd ed. Philadelphia, PA: Lea and Febiger; 1990

15. King PT. Painful disorders of the respiratory system. In: Waldman SD, editor. Pain Management, 2nd ed. Philadelphia, PA: Elsevier; 2011:1763-1771.

16. Paintal AS. Thoracic receptors connected with sensation. Br Med Bull. 1977;33(2):169-174.

17. Coleridge JC, Coleridge HM. Functional role of pulmonary rapidly adapting receptors and lung $\mathrm{C}$ fibers. In: Lahiri S, Forster RE, Davies RO, Pack A, editors. Chemoreceptors and Reflexes in Breathing. New York, NY: Oxford University Press; 1989:287-292.

18. Paintal AS. Vagal sensory receptors and their reflex effects. Physiol Rev. 1973;53(1):159-227.

19. Murray JF, Gebhart G. Chest pain. In: Murray JF, Nadal JA, editors. Textbook of Respiratory Medicine, 3rd ed. Philadelphia, PA: WB Saunders; 2000:567-571.

20. Coleridge JC, Coleridge HM. Afferent vagal C fibre innervation of the lungs and airways and its functional significance. Rev Physiol Biochem Pharmacol. 1984;99:1-110.

21. King PT, Holdsworth SR, Freezer NJ, Villanueva E, Holmes PW. Characterisation of the onset and presenting clinical features of adult bronchiectasis. Respir Med. 2006;100(12):2183-2189. 
22. Chang AB, Bilton D. Exacerbations in cystic fibrosis: 4 - Non-cystic fibrosis bronchiectasis. Thorax. 2008;63(3):269-276.

23. O'Donnell AE, Barker AF, Ilowite JS, Fick RB. Treatment of idiopathic bronchiectasis with aerosolized recombinant human DNase I. rhDNase Study Group. Chest. 1998;113(5):1329-1334.

24. Cymbala AA, Edmonds LC, Bauer MA, et al. The disease-modifying effects of twice-weekly oral azithromycin in patients with bronchiectasis. Treat Respir Med. 2005;4(2):117-122.

25. Rodriguez-Roisin R. Toward a consensus definition for COPD exacerbations. Chest. 2000;117(5 Suppl 2):398S-401S.

26. Martínez-García MA, Soler-Cataluña JJ, Perpiñá-Tordera M, Román-Sánchez P, Soriano J. Factors associated with lung function decline in adult patients with stable non-cystic fibrosis bronchiectasis. Chest. 2007;132(5):1565-1572.

27. Levene DL. Pain arising from intrathoracic structures. Chest Pain: An Integrated Diagnostic Approach. Philadelphia, PA: Lea and Febiger; 1977:71-75.
28. Nicotra MB, Rivera M, Dale AM, Shepherd R, Carter R. Clinical, pathophysiologic, and microbiologic characterization of bronchiectasis in an aging cohort. Chest. 1995;108(4):955-961.

29. Fuschillo S, De Felice A, Balzano G. Mucosal inflammation in idiopathic bronchiectasis: cellular and molecular mechanisms. Eur Respir J. 2008;31(2):396-406.

30. Zakrzewski JT, Barnes NC, Costello JF, Piper PJ. Lipid mediators in cystic fibrosis and chronic obstructive pulmonary disease. Am Rev Respir Dis. 1987;136(3):779-782.

31. King PT. Non-pleuritic chest pain and recurrent lobar collapse. Respir Med CME. 2009;2(3):125-127.

32. Flasar MH, Goldberg E. Acute abdominal pain. Med Clin North Am. 2006;90(3):481-503.
International Journal of General Medicine

\section{Publish your work in this journal}

The International Journal of General Medicine is an international, peer-reviewed open-access journal that focuses on general and internal medicine, pathogenesis, epidemiology, diagnosis, monitoring and treatment protocols. The journal is characterized by the rapid reporting of reviews, original research and clinical studies across all disease areas.

\section{Dovepress}

A key focus is the elucidation of disease processes and management protocols resulting in improved outcomes for the patient.The manuscript management system is completely online and includes a very quick and fair peer-review system. Visit http://www.dovepress.com/ testimonials.php to read real quotes from published authors. 